\title{
Heat exchanger for profound hypothermia ${ }^{1}$
}

\author{
M. VAŠULÍN AND O. OŠLEJSEK \\ From the II Surgical Clinic, J. E. Purkynè University, Brno, and the \\ Research and Development Institute of Electrical Machinery, Brno, Czechoslovakia
}

Induced hypothermia makes it possible to interrupt the circulation, open the heart and redress some of its disorders under visual control (Bigelow, Callaghan, and Hopps, 1950 ; Bigelow, Lindsay, and Greenwood, 1950).

'Moderate' hypothermia, usually achieved by surface cooling, only permits circulatory osclusion for eight or at most 10 minutes (Navrátil and Vašulín, 1956, 1957). Reduction of the body temperature below $28^{\circ} \mathrm{C}$. entails a great risk of ventricular fibrillation. The use of a heart/lung machine is necessary to support the circulation should lower temperatures be required. Indeed, only by incorporating a heat exchanger in a heart/ lung machine is it possible to achieve safely profound degrees of hypothermia (Ross, 1954 ; Drew, Keen, and Benazon, 1959 ; Drew and Anderson, 1959; Gollan, Grace, Schell, Tysinger, and Feaster, 1955 ; Sealy, Brown, and Young, 1958 ; Sealy, Young, Brown, Smith, and Lesage, 1960). This combination has the following advantages. Organs essential to life and sensitive to lack of oxygen can be cooled quickly and safely. The metabolic requirements of these organs and of the body as a whole are decreased. As the temperature falls the circulatory flow rate may be decreased and the duration of perfusion increased. At a low enough temperature the circulation may be stopped completely for considerable periods (Gordon, Meyer, and Jones, 1960).

Most heat exchangers (Brown, Smith, and Emmons, 1958; Shields and Lewis, 1959; DeGasperis, Demetz, and Donatelli, 1963; Esmond, Attar, Stram, Demetriades, Jurf, Gold, and Cowley, 1961 ; Urschel, Greenberg, and Roth, 1960) in common use have one or more of the following disadvantages:

(i) They are bulky in size, of low efficiency, and, having a high priming volume, are extravagant of blood. The priming requirements cannot be adapted to those of the patient.

(ii) Although some are 'disposable', most are difficult to clean and resterilize as well as to debubble when priming.

1 Czechoslovak patent No. 108639 ; P.V. $2991 / 62$; P.V. 2586/63 (iii) Welded and other joints may be imperfect or become so with use.

(iv) Manufacture is relatively time-consuming and costly.

The design must eliminate as many of these disadvantages as possible and ensure that the development of unnecessary turbulence and loss of pressure in the circulation is avoided. Using a system of alternating metal and plastic screens, Messrs Hellige-France of Strasbourg (Estanove, Gounot, and Marion, 1960 ; Vadot, 1962) partly achieved these aims. In their heat exchanger there are parallel channels so arranged that the systems in which the blood and water flow are perpendicular to each other.

Our heat exchanger is a development from this ; it also features cross-flow of blood and water with a relatively large area for heat transfer. It consists of packs of two screens of which screen A (Fig. 1) is of metal, conducting heat well, and screen $B$ is of plastic material, for perfect sealing. $A$ pair of packs $A B$ and $A^{\prime} B^{\prime}$ forms one water and one blood channel. The capacity of the exchanger can be changed by varying the number of assembled packs of screens.

Figure 1 also shows how the screens are assembled into packs and entire groups. The assembly always repeats itself after eight screens, mark $Z$ being on the identical side. Thus two blood and two water channels separated from each other arise between eight screens. This is facilitated by the massive foundation plates provided with inlets and outlets for both liquids by the relatively rigid metal screens. Along the entire wetted periphery of the sealing screens there is a tiny continuous projection to improve sealing. These easily sterilized screens are placed in their respective order and position on the guiding rod protruding from the bottom foundation plate and are compressed by tightening the screw 'controlled' by a spring galvanometer (Figs 2 and 3). This ensures perfectly tight separation of the blood and water circuits.

This series type heat exchanger is especially suited for clinical use ; it operates efficiently and quickly; $160 \mathrm{ml}$. of blood will suffice for 16 


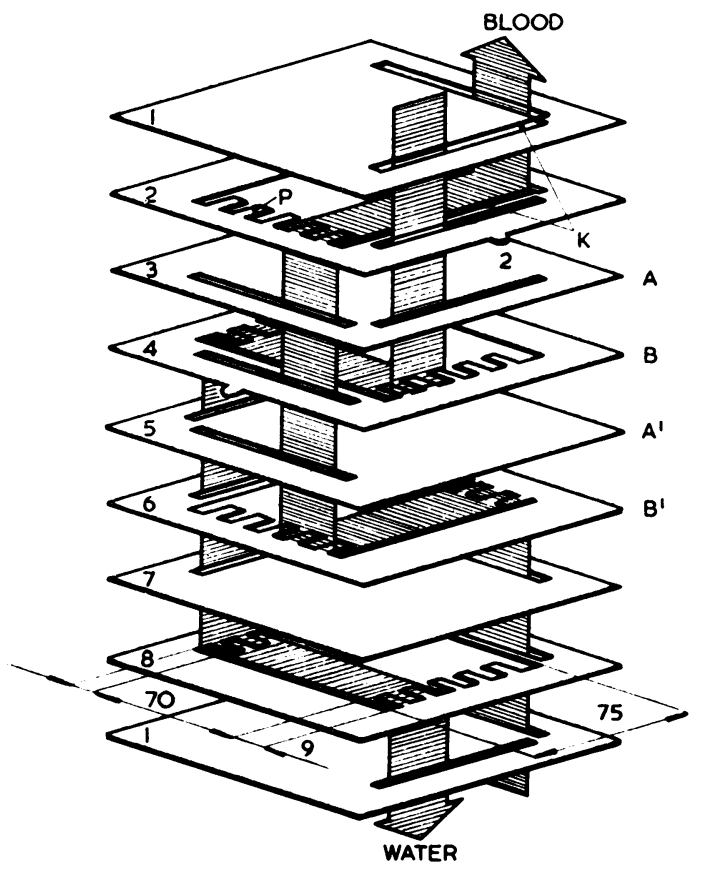

FIG. 1. Slot-type exchanger featuring cross and counter flow of heat-changing liquids.

F!G. 3. Assembled heat exchanger
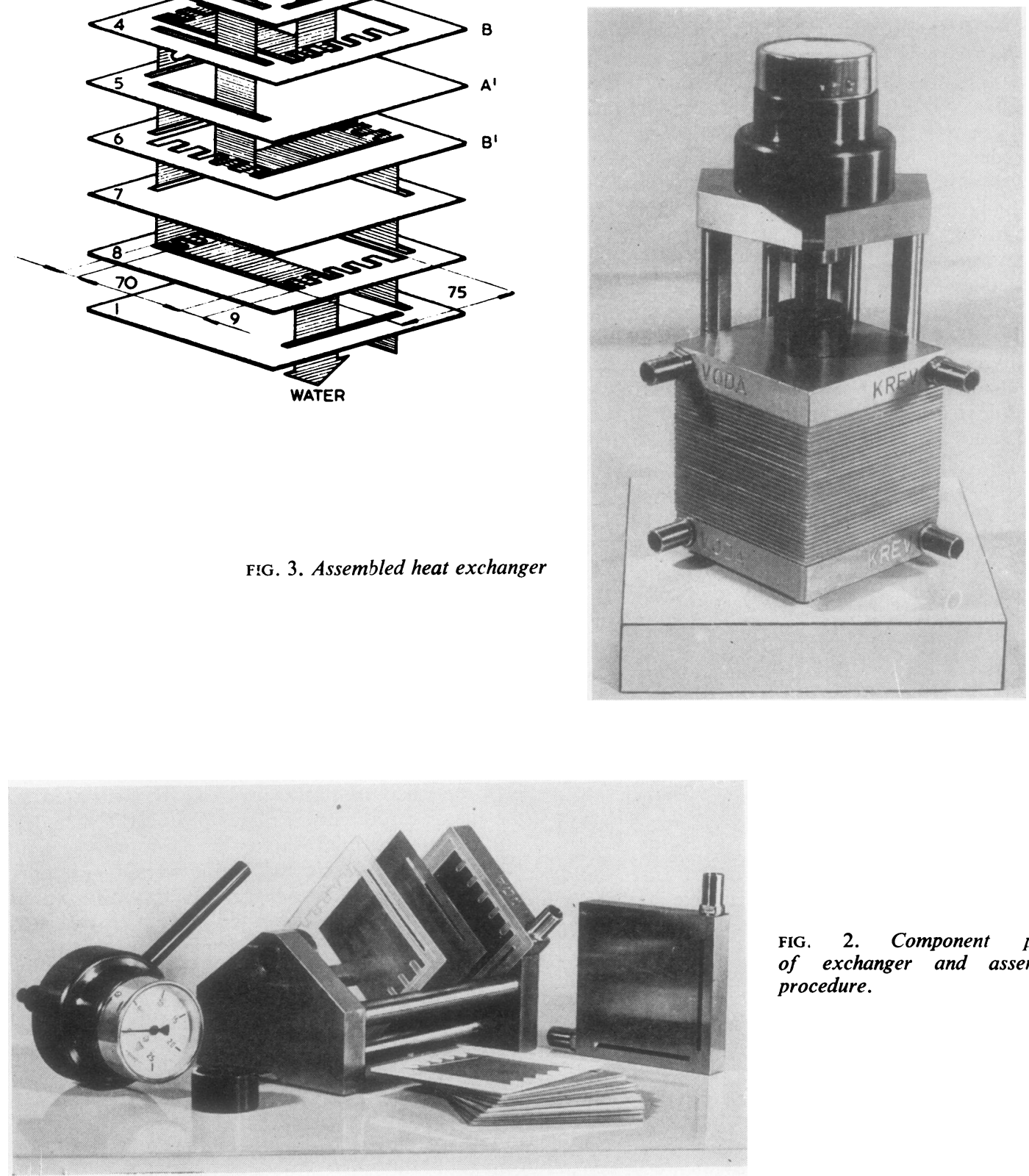

FIG. 2. Component parts of exchanger and assembly procedure. 
segments. It can be assembled, taken apart, cleaned, sterilized, and reassembled quickly. Its design is such that there is no significant loss of pressure in the pump-heat-exchanger-patient circuit, a feature of importance when using profound hypothermia. Adjustment to offset loss of pressure may be made if desired by varying the number of sealing screens used; as the average drop in pressure in the water circuit will be substantially greater than that in the blood circuit, penetration of water into the blood cannot occur.

Compared with other types, this heat exchanger has the highest value for the overall coefficient of heat transfer, because its flow rate approaches the limit where turbulent flow arises and because of the hydraulic diameter. For instance, studies show that in comparison with the Esmond exchanger ours has more than four times the overall coefficient of heat transfer.

The basic requirement of absolute separation of the blood and water circulation paths has been repeatedly proved, both by hydrostatic and chemical tests. In the latter, one circuit was filled with a $1 \%$ solution of nickel sulphate and the other with distilled water; tested at different temperatures and flow rates the nickel ions could never be found in the other circuit.

Since no trouble was encountered using this heat exchanger during 23 experiments on animals, it was first used clinically on 20 December 1961 (Navrátil et al., 1962) and until the time of writing it has proved satisfactory in more than 320 operations.

\section{SUMMARY}

A new type of heat exchanger suited for profound hypothermia is described. It is distinguished by a small priming volume and a high specific heat output. It is of 'slot type' and features counter flow, consisting of plate screens which can be cleaned and sterilized easily. After thorough testing of its hydraulic and thermal properties it was found satisfactory in animal experiments and is now in regular clinical use.

\section{REFERENCES}

Bigelow, W. G., Callaghan, J. C., and Hopps, J. A. (1950). General hypothermia for experimental intracardiac surgery. Ann. Surg. 132, 531 .

- Lindsay, W. K., and Greenwood, W. F. (1950). Hypothermia ; its possible role in cardiac surgery. Ibid., 132, 849 .

Brown, I. W., Smith, W. W., and Emmons, W. O. (1958). An efficient blood heat exchanger for use with extracorporeal circulation. Surgery, 44, 372.

Drew, C. E., and Anderson, I. M. (1959). Profound hypothermia in cardiac surgery; report of three cases. Lancet, $1,748$. Keen, G., and Benazon, D. B. (1959). Profound hypothermia. Ibit., 1,745 .

Esmond, W. G., Attar, S., Stram, J., Demetriades, A. D., Jurf, A. Gold, M. I., and Cowley, R. A. (1961). Profound hypothermia with simplified equipment ; a disposable stainless steel heat exchanger of high efficiency. J. thorac. cardiovasc. Surg., 42, 563.

Estanove, J. F., Gounot, J., and Marion, P. (1960). Echangeur de temp'rature pour hypothermie profonde. Ann. Chir., 14, 607.

DeGasperis, A., Demetz, A., and Donatelli, R. (1963). An ultrarapid heat exchanger for profound hypothermia. J. thorac. cardiovasc. Surg., 45,343 .

Gollan, F., Grace, J. T., Schell, M. W., Tysinger, D. S., and Feaster, L. B. (1955). Left heart surgery in dogs during respiratory and cardiac arrest of body temperatures below $10^{\circ} \mathrm{C}$. Surgery, 38, 363.

Gordon, A. S., Meyer, B. W., and Jones, J. C. (196?). Open-heart surgery using deep hypothermia without an oxygenator. $J$. thorac. cardiovasc. Surg. 40,787.

Navrátil, J., and Vašulín, M. (1956). Experimentální chirurgie srdce v hypothermii (Experimental cardiac surgery in hypothermia). Rozhl. Chir., 35, 88.

(1957). The operation of cardiac defects in the open and empty heart using hypothermia. Rev. Czechoslovak Med., 3, 315. et al. (1962). Zkušenosti s operacemi srdexnich vad $v$ hluboké hypothermii (Experience with operations of heart defects in profound hypothermia). CLC (Czechoslovak Medical Journal), No. found hypothe

Ross, D. N. (1954). Hypothermia. Part I. - A technique of blood stream cooling. Guy's Hosp. Rep., $103,97$.

Sealy, W. C., Brown, I. W., and Young, W. G. (1958). A report in the use of both extracorporeal circulation and hypothermia for open heart surgery. Ann. Surg., 147, 603.

- Young, W. G., Brown, I. W., Smith, W. W., and Lesage, A. M. (1960).' Profound hypothermia combined with extracorporeal circulation for open heart surgery. Surgery, 48, 432.

Shields, T. W., and Lewis, F. J. (1959). Rapid cooling and surgery at temperatures below $20^{\circ} \mathrm{C}$. Ibid., $46,164$.

Urschel, H. C., Greenberg, J. J., and Roth, E. J. (1960). Rapid hypothermia : an improved extracorporeal method. J. thorac. cardiovasc. Surg., 39, 318.

Vadot, L. (1962). Échangeur de chaleur à surface ajustable au poids du sujet. Ann Chir. thorac. cardiovasc., 1, 519. [In Ann. Chir. 16.] 